\begin{tabular}{|c|c|c|}
\hline $\begin{array}{l}\text { UnD } \\
\text { Universitas } \\
\text { Ahmad Dahlan }\end{array}$ & $\begin{array}{c}\text { Jurnal Fokus Manajemen Bisnis } \\
\text { Volume 11, Nomor 2, September 2021, Halaman 271-286 } \\
\text { https://doi.org/10.12928//fokus.v11i2.3909 } \\
\text { http://journal2.uad.ac.id/index.php/fokus }\end{array}$ & $\begin{array}{c}\mathrm{F} \oplus \mathrm{KUS} \\
\end{array}$ \\
\hline
\end{tabular}

\title{
PENGARUH WORKPLACE BULLYING DAN PERCEIVED SUPERVISOR SUPPORT TERHADAP TURNOVER INTENTION
}

\author{
Candra Vionela Merdiana ${ }^{1,}{ }^{*}$, Bagus Gumelar ${ }^{2}$ \\ Universitas Ahmad Dahlan \\ candra.vm@mgm.uad.ac.id \\ *Correspondent Author
}

\section{ARTICLE INFO ABSTRACT}

Article History

Received 2021-03-31

Revised 2021-09-03

Accepted 2021-09-03

Keywords

Workplace Bullying

Perceived Supervisor Support

Turnover Intention
This study aims to analyze the effect of Workplace Bullying and Perceived Supervisor Support on Turnover Intention of Employees of a Private University in Yogyakarta.. This research is a quantitative research through a survey method using a questionnaire. The sample in this study were some employees of a Private University in Yogyakarta with a total sample of 71 employees. The sampling technique in this study is non-probability sampling with the Incidental Sampling method. The unit of analysis used in this study is the individual, namely the employee of a Private University in Yogyakarta. This study uses an instrument test conducted with validity and reliability tests as a condition before testing the hypothesis, while the multiple regression analysis method is used to test the hypothesis. The results of hypothesis testing using multiple regression analysis indicate that the first hypothesis is accepted, namely the effect of work bullying has a positive and significant effect on turnover intentions, the second hypothesis is rejected, namely the influence of supervisor support perceptions has no significant effect on turnover intention.

This is an open-access article under the CC-BY-SA license.

\section{Pendahuluan}

Sumber Daya Manusia (SDM) merupakan aset berharga yang harus dimiliki oleh perusahaan, karena SDM atau manusia menjadi unsur yang sangat penting dalam berbagai kegiatan yang dilakukan (Hasibuan, 2003) sebagai penggerak dan penunjang dalam tercapainya visi, misi, serta tujuan perusahaan. Dukungan yang optimal dan pengelolaan yang baik dalam sumber daya manusia yang dimiliki perusahaan, maka akan tercapai keunggulan kompetitif. Turnover merupakan salah satu cerminan kinerja organisasi atau perusahaan dan juga untuk mengukur kestabilan suatu perusahaan atau organisasi. Ada saatnya perpindahan karyawan sangat dibutuhkan perusahaan yaitu saat produktivitas yang dimiliki karyawan rendah. Namun sebaliknya, apabila SDM tidak dikelola dan tidak adanya dukungan yang baik dari perusahaan, maka SDM yang dimiliki akan merasa tidak puas dalam bekerja karena tidak adanya perhatian baik dari segi gaji, fasilitas, dan lainnya. Ketika karyawan tidak mendapatkan apa yang menjadi harapannya maka karyawan akan cenderung bermalasmalasan dan kurang semangat dalam bekerja dan akhirnya terpikirkan untuk mencari pekerjaan lain atau bahkan mengundurkan diri dari perusahaan tersebut.

Banyak hal yang menjadi permasalahan terkait dengan isu-isu SDM salah satunya adalah turnover intention. Menurut Robbins \& Judge (2013) turnover sebagai pemberhentian pegawai yang bersifat permanen dari perusahaan baik yang dilakukan oleh pegawai sendiri 
atau secara sukarela maupun yang dilakukan oleh perusahaan. Menurut Mahardika \& Wibawa (2015) tingkat turnover karyawan yang tinggi merupakan ukuran yang sering digunakan sebagai indikasi adanya masalah yang mendasar pada organisasi. Keinginan atau niat berpindah karyawan yang terlalu tinggi dapat menciptakan ketidakstabilan terhadap kondisi perusahaan atau organisasi, juga peningkatan biaya rekrutmen yang juga akan meningkatkan kerugian yang besar bagi perusahaan atau organisasi. Diperkuat oleh Ferdinand (2010) bahwa turnover intention menunjukkan keinginan untuk tetap atau meninggalkan organisasi secara konsisten berhubungan dengan perpindahan pekerjaan. Selain itu turnover intention diantara karyawan mempunyai korelasi yang kuat dengan keinginan atau niat untuk keluar, mencari pekerjaan dan berpikir untuk keluar. Oleh karena itu, suatu perusahaan dituntut untuk dapat mempertahankan karyawannya, seperti mampu memberikan balas jasa dan apresiasi yang tinggi dan memahami hal-hal yang mampu membuat karyawannya betah untuk tetap bekerja tanpa menurunkan kinerja perusahaan tersebut secara keseluruhan.

Pada penelitian yang terdahulu, turnover intention paling banyak diteliti pada perusahaan manufaktur seperti penelitian oleh Aljawazneh \& Smadi (2017), Taufiq (2017), Coetzee \& van Dyk (2018). Selain di perusahaan manufaktur, penelitian terdahulu juga meneliti tentang turnover intention dengan objek penelitian di hotel yaitu penelitian oleh Arici (2018) dan pada kantor swasta dan pemerintahan pada penelitian yang dilakukan RosarioHernandez et al. (2018). Berdasarkan penelitian terdahulu tersebut, isu mengenai turnover intention ternyata tidak banyak yang meneliti di perusahaan jasa atau di lingkungan akademisi. Dengan melihat fenomena beberapa tahun ini, banyak karyawan sebuah universitas swasta di Yogyakarta baik tenaga pendidik maupun dosen mengundurkan diri secara sukarela maupun secara tidak sukarela. Banyak alasan yang menyebabkan timbulnya turnover intention ini dan diantaranya adalah keinginan untuk mendapatkan pekerjaan yang lebih baik atau sudah mendapatkan tempat kerja yang lebih baik, keinginan untuk meninggalkan organisasi secara sukarela karena sakit dan keinginan untuk keluar karena merasa diintimidasi atasan maupun rekan kerja.

Selain alasan yang disebutkan diatas turnover intention juga dipengaruhi oleh beberapa variabel antara lain menurut Glambek et al. (2014), Coetzee \& van Dyk (2018), RosarioHernandez et al. (2018) bahwa workplace bullying berpengaruh positif terhadap turnover intention. Hal ini seiring dengan fenomena perundungan yang menjadi topik sosial yang sedang ramai dibicarakan di seluruh dunia salah satunya negara Amerika yang mengadakan survei melalui workplace bullying institute pada tahun 2017 dimana menunjukkan hasil bahwa orang Amerika yang mengalami perundungan di tempat kerja sebesar 19\%, yang telah menyaksikan adanya perundungan di tempat kerja sebesar 19\%, sedangkan sisanya sebesar $62 \%$ menyadari adanya perundungan di tempat kerja. Undang-undang ketenagakerjaan di negara maju yang jelas dan ketat untuk melindungi para karyawannya dari berbagai pelecehan dan intimidasi di tempat kerja juga tidak menjamin tidak terjadi adanya perundungan. Sama halnya dengan yang terjadi di negara berkembang seperti di Indonesia, dimana pemerintah saat ini juga konsen akan masalah perundungan secara umum, hingga dimunculkannya Undang-Undang Nomor 35 Tahun 2015 tentang perubahan atas UndangUndang Nomor 23 Tahun 2002 tentang Perlindungan Anak dan Iklan-Iklan Layanan Masyarakat mengenai "Stop Bullying".

Perundungan dapat menjadi awal munculnya masalah dalam suatu organisasi yang sering terjadi saat ini yang dapat menyebabkan keinginan karyawan untuk keluar menjadi tinggi. Perundungan dapat dialami oleh siapa saja dan dapat terjadi dimana saja, terkadang seseorang tanpa disadari pernah menjadi korban perundungan. Seseorang harus sedikit peka dengan apa yang terjadi di sekitarnya, karena perilaku perundungan sudah menjadi fenomena yang bahkan pelakunya tidak merasa bahwa dia telah melakukan tindakan perundungan. Perundungan dapat terjadi baik di tempat kerja, di lingkungan akademisi, dan 
lingkungan sosial bahkan dengan semakin majunya teknologi, perundungan sudah menjangkiti media sosial. Peraturan perundang-undangan mengenai ketenagakerjaan di Indonesia terdapat pada Undang-Undang Republik Indonesia Nomor 21 Tahun 1999 tentang Pengesahan ILO Convention Nomor 111 Concerning Discrimination in Respect of Employment and Occupation (Konvensi ILO Mengenai Diskriminasi dalam Pekerjaan dan Jabatan) yang mengatur mengenai larangan untuk melakukan segala macam bentuk diskriminasi dan Undang-Undang Nomor 13 Tahun 2003 tentang Ketenagakerjaan yang mengatur mengenai berbagai macam perlindungan seperti jaminan kesehatan, sosial, dan upah. Sedangkan di Indonesia belum ada hukum dan perundang-undangan yang secara spesifik mengatur masalah hubungan atau komunikasi secara personal antar karyawan, tidak adanya perlindungan hukum yang mengatur perilaku antarpersonal karyawan membuat perilaku perundungan masih terjadi di tempat kerja khususnya di negara berkembang seperti di Indonesia masih tinggi. Hal ini diperkuat oleh Kaisar \& Seventy (2015) yang menjelaskan bahwa kurangnya perlindungan yang spesifik terhadap para karyawan mengenai pelecehan verbal dan perilaku perundungan di tempat kerja masih sering terjadi di negara berkembang.

Perundungan di tempat kerja juga harus menjadi perhatian khusus baik dari segi karyawan maupun pemimpin atau atasan, karena kita tahu bahwa perilaku perundungan ini akan berdampak buruk pada kinerja perusahaan atau organisasi. Karyawan yang mendapatkan perlakuan yang buruk di lingkungan kerjanya seperti perilaku perundungan ini, mereka akan merasakan perasaan tertekan dan merasa terintimidasi yang pada akhirnya akan membuat mereka stres bahkan dapat mengalami depresi. Selain itu, dengan adanya perilaku maupun tindakan perundungan tempat kerja juga dapat menyebabkan menurunnya semangat kerja, produktivitas yang rendah, menurunnya kualitas kerja karyawan, komitmen karyawan yang rendah pada perusahaan atau organisasi dan bahkan penurunan kepuasaan kerja yang akan menaikkan intensitas keinginan karyawan untuk keluar atau berpindah (turnover intention) menjadi tinggi.

Menurut Einarsen et al. (2009) perundungan di tempat kerja lebih mengacu pada suatu situasi dimana satu atau lebih individu menerima atau mengalami tindakan atau perilaku negatif yang terus-menerus dan berulang-ulang yang dilakukan dengan tujuan untuk mengganggu dan menyakiti korbannya yang lebih lemah. Apabila karyawan secara terus menerus mendapatkan perundungan di tempat kerja baik perundungan secara fisik seperti ancaman kekerasan, kekerasan fisik atau penganiayaan, perundungan terkait personal seperti membuat komentar atau penghinaan di depan publik, adanya rumor atau gosip yang tidak sesuai bahkan fitnah maupun perundungan terkait pekerjaan seperti menetapkan beban kerja secara berlebihan, pengawasan yang extreme terhadap penugasan, tidak adanya feedback yang baik dari pimpinannya (Einarsen et al., 2009). Hal ini akan semakin membuat karyawan merasa tidak nyaman berada di lingkungan kerjanya dan memiliki keinginan yang kuat untuk pindah atau keluar kerja dari tempat dimana dia bekerja saat ini. Beberapa studi penelitian menunjukkan bahwa paparan bullying atau perundungan di tempat kerja terkait dengan meninggalkan organisasi (Mathisen, et al., 2008; Berthelsen et al., 2011; Coetzee \& van Dyk, 2018). Berthelsen et al. (2011) menemukan selama lebih dari dua tahun bahwa karyawan yang mengalami perundungan di tempat kerja lebih sering terjadi daripada karyawan yang tidak terkena perilaku perundungan, sehingga hal tersebut menunjukkan pengaruh yang sangat signifikan antara workplace bullying terhadap turnover intention.

Selanjutnya yang mempengaruhi turnover intention selain workplace bullying ternyata perceived supervisor support juga ada pengaruhnya terhadap turnover intention. Menurut Lim \& Boger (2005) dukungan supervisor yang dirasa karyawan atau persepsi dukungan supervisor yang buruk akan sangat merugikan perusahaan karena dapat mengakibatkan tingkat turnover yang tinggi, absensi dan kinerja yang rendah, sehingga dapat mengurangi keberhasilan organisasi atau perusahaan secara menyeluruh. Temuan penelitian mengenai pengaruh perceived supervisor support terhadap turnover intention pada penelitian Kalidass \& 
Bahron (2015) menemukan bahwa perceived supervisor support berpengaruh negatif terhadap turnover intention pada karyawan hotel. Perceived supervisor support menjadi salah satu faktor penting dalam memprediksi turnover intention, semakin sedikit dukungan dari supervisor, semakin semakin besar kemungkinan karyawan akan meninggalkan organisasi tempat kerja mereka (Maertz Jr et al., 2007). Selain itu penelitian yang dilakukan Taufiq (2017) menunjukkan hasil persepsi dukungan supervisor berpengaruh negatif dan signifikan terhadap turnover intention yang mana semakin tinggi tingkat dukungan supervisor yang dirasa karyawan, maka akan semakin rendah niatan atau keinginan karyawan untuk keluar atau berpindah dari tempat kerjanya. Menurut Eisenberger et al. (2002) perceived supervisor support (PSS) mengacu pada pendapat yang dimiliki pekerja tentang apakah manajer mereka menghargai kontribusi mereka dan peduli terhadap kesejahteraan mereka. Dengan adanya dukungan dari supervisor atau manajer, maka akan meningkatkan kinerja suatu organisasi, sehingga keinginan karyawan untuk keluar atau berpindah kerja akan semakin kecil. Hal ini juga didukung oleh penelitian yang dilakukan oleh Arici (2018) dimana perceived supervisor support mempunyai pengaruh negatif terhadap turnover intention.

Objek penelitian ini adalah karyawan di sebuah universitas swasta di Yogyakarta, dimana karyawan merupakan bagian dari sumber daya manusia yang menopang keberlanjutan suatu organisasi atau universitas. Karyawan disini adalah tenaga pendidik yang terdiri dari semua divisi dari tingkat atas sampai bawah. Sedangkan unit analisis dari penelitian ini adalah individu. Alasan meneliti pada karyawan pada universitas ini adalah karena beberapa tahun terdapat fenomena baik tenaga pendidik maupun dosen yang mengundurkan diri secara sukarela maupun secara tidak sukarela. Banyak alasan yang menyebabkan timbulnya turnover intention ini dan diantaranya adalah keinginan untuk mendapatkan pekerjaan yang lebih baik atau sudah mendapatkan tempat kerja yang lebih baik, keinginan untuk meninggalkan universitas secara sukarela karena sakit dan keinginan untuk keluar karena merasa diintimidasi atasan ataupun rekan kerja. Penelitian ini akan menganalisa bagaimana pengaruh workplace bullying terhadap turnover intention dan pengaruh perceived supervisor support terhadap turnover intention dalam konteks individu khususnya karyawan (tenaga pendidik).

\section{Review Literatur dan Hipotesis}

\subsection{Landasan Teori}

\subsubsection{Turnover Intention}

Turnover intention adalah keinginan keluar yang dilakukan karyawan untuk berpindah kerja dari organisasi tersebut dengan menerima upah penghasilan (Melky, 2015). Sedangkan teori lain yang dikemukakan oleh Tett \& Meyer (1993) turnover intention mengacu pada kemauan sadar dan terencana untuk meninggalkan organisasi. Keinginan seseorang keluar dari organisasi yaitu evaluasi, posisi seseorang saat ini berkenaan dengan ketidakpuasan yang memicu keinginan seseorang keluar dan mencari pekerjaan lain juga dapat dikatakan turnover intention (Luthans, 2012). Disisi lain menurut Chun (2012) turnover intention adalah kecenderungan karyawan untuk berhenti bekerja dari pekerjaannya.

Turnover intention bahwa dibagi menjadi enam jenis menurut Mathis \& Jackson (2006) antara lain: Pertama, turnover secara sukarela, yaitu keinginan karyawan untuk keluar atau berpindah kerja atas keinginannya sendiri. Biasanya karena ada peluang karir yang lebih bagus, atau gaji yang lebih tinggi, merupakan penyebab dari jenis turnover ini. Kedua, turnover secara tidak sukarela adalah pemecatan karyawan atau pemutusan hubungan kerja (PHK) baik karena kinerja buruk, pelanggaran peraturan kerja maupun perampingan. Ketiga, turnover fungsional merupakan keinginan keluar yang dilakukan oleh karyawan dikarenakan karyawan tersebut memiliki kinerja lebih rendah dari pada yang lain. Di samping itu, turnover fungsional juga terjadi karena 
karyawan tersebut kurang dapat diandalkan oleh organisasi dan berpotensi mengganggu karyawan yang memiliki kinerja baik. Keempat, turnover disfungsional merupakan keinginan keluar yang dilakukan oleh karyawan penting, memiliki kinerja yang tinggi, dan meninggalkan organisasi pada saat kondisi yang genting. Kelima, turnover yang dapat dikendalikan yaitu suatu faktor yang muncul dan dapat dipengaruhi oleh pemberi kerja. Tujuannya yaitu mempengaruhi suatu organisasi dan memberikan peningkatan fasilitas, seperti pemberian bonus, peningkatan gaji, dan promosi jabatan. Keenam, turnover yang tidak dapat dikendalikan biasanya disebabkan karena alasan diluar pengaruh pemberi kerja.

Ada beberapa indikasi keinginan untuk keluar menurut Dysvik \& Kuvaas (2010) antara lain keinginan mencari pekerjaan di tahun depan, keinginan untuk keluar setelah masa bekerja 12 bulan, berusaha mencari pekerjaan 3 tahun kedepan, pekerjaan yang tidak mempunyai prospek, keinginan untuk keluar pekerjaan saat ini, dan keinginan untuk mencari pekerjaan lain. Menurut Chen et al. (2002) turnover intention adalah kecenderungan atau tingkat dimana seorang karyawan memiliki kemungkinan untuk meninggalkan perusahaan. Selanjutnya, Chen et al. (2002) menjelaskan turnover intention memiliki 3 indikator yang mana masing-masing indikator tersebut memiliki 3 item pertanyaan. Indikator turnover intention meliputi: 1) Pikiran-pikiran untuk keluar, 2) Keinginan untuk mencari lowongan atau pekerjaan lain, dan 3) Adanya keinginan untuk meninggalkan organisasi.

\subsection{Workplace Bullying}

Menurut Einarsen et al. (2009) bahwa istilah bullying di tempat kerja merupakan suatu kondisi atau situasi dimana satu atau lebih individu menerima atau mengalami tindakan negatif yang terus-menerus dan berulang-ulang dengan maksud untuk menyakiti. Menurut Yun et al. (2014) bahwa bullying di tempat kerja dapat dianggap bentuk kekerasan di tempat kerja, termasuk kekerasan verbal, ancaman, pengecualian, penghinaan, kritik keras, mengolok-olok, mengambil kesempatan, menggoda, mengganggu, intersepsi informasi, dan melanggar masalah privasi.

Einarsen et al. (2009) membagi perundungan di tempat kerja menjadi 3 jenis yaitu person related bullying atau perundungan terkait dengan individu atau karyawan itu sendiri, work related bullying atau perundungan terkait dengan pekerjaan mereka, dan physically intimidating bullying atau perundungan secara fisik. Sedangkan menurut Keashly \& Neuman (2004) membagi bullying di tempat kerja menjadi 2 jenis yaitu ancaman terhadap posisi pribadi misalnya adanya penghinaan di depan publik, ancaman secara verbal, menghindari target, dan menyebarkan rumor atau gosip. Ancaman terhadap posisi pekerjaan secara profesional, seperti merahasiakan informasi yang penting terkait pekerjaan, obstruksi kerja, menolak akses ke pelatihan, tidak ada feedback yang konstruktif, dan menetapkan tugas atau beban kerja secara berlebihan.

Bullying di tempat kerja memiliki dampak yang merugikan tidak hanya bagi karyawan tetapi juga untuk organisasi dan masyarakat secara lebih luas. Hershcovis et al. (2015) menyebutkan ada 3 kategori efek dari perisakan di tempat kerja: Pertama, biaya SDM (human cost). Target working bullying mengalami penurunan kesehatan dan kesejahteraan yang signifikan. Para karyawan yang mengalami perundungan melaporkan peningkatan tekanan psikologis, kejenuhan dan kelelahan emosional yang tinggi termasuk kecemasan, depresi, dan emosi negatif lainnya. Kedua, biaya organisasi (organizational cost). Biaya yang dikeluarkan untuk sumber daya manusia akibat working bullying memiliki dampak pada organisasi. Korban perundungan akan mengalami gangguan emosional dan fisiologis yang memperbesar kemungkinan untuk tidak hadir karena sakit, sedangkan korban yang tetap berangkat kerja akan menunjukkan penurunan pada kinerja, kreativitas, dan perilaku organisasi. Ketiga, 
biaya sebab akibat (spillover/crossover cost). Atasan yang kecewa dengan lingkungan kerja yang buruk akibat terjadinya working bullying lebih memungkinkan melimpahkan kekesalannya kepada karyawan atau bawahannya. Bawahan yang kecewa ini akan membawa kekesalannya lagi ke rumah sehingga hal negatif ini akan terus berlanjut.

Workplace bullying dikutip dari Negative Acts Questionnair e-Revised (NAQ-R) oleh Einarsen et al. (2009) memiliki 3 indikator yang mana pada indikator pertama terdiri dari 7 item pertanyaan, indikator kedua terdiri dari 12 item pertanyaan, dan indikator ketiga terdiri dari 3 item pertanyaan. Indikator dari workplace bullying antara lain 1) Person related bullying atau perundungan terkait dengan individu atau karyawan itu sendiri, 2) Work related bullying atau perundungan terkait dengan pekerjaan mereka, dan 3) Physically intimidating bullying atau perundungan secara fisik.

\subsubsection{Perceived Supervisor Support}

Menurut Eisenberger et al. (2002) perceived supervisor support (PSS) mengacu pada pendapat yang dimiliki pekerja tentang apakah manajer mereka menghargai kontribusi mereka dan peduli terhadap kesejahteraan mereka. Dengan adanya dukungan dari supervisor atau manajer, maka akan meningkatkan kinerja suatu organisasi. Hal ini sesuai dengan pendapatan dari Dasgupta et al. (2012) yaitu ketika supervisor memiliki empati dan simpati terhadap karyawannya, maka dukungan supervisor yang dirasa karyawan akan mengurangi ketidakhadiran karyawan dan meningkatkan kepuasan kerja, komitmen, kinerja, dan produktivitas karyawan. Menurut Feinberg (2013) dukungan supervisor dapat ditunjukkan dengan perilaku sebagai berikut: 1) membantu menetapkan tujuan untuk menerapkan pelatihan, 2) memberikan bantuan ketika mencoba perilaku baru, dan 3) umpan balik pada kinerja tugas. Perceived supervisor support dikutip dari Bacharach \& Bamberger (2007) terdiri dari tiga indikator yang mana pada indikator pertama memiliki 2 item pertanyaan, indikator kedua dan ketiga masing-masing hanya memiliki 1 item pertanyaan. Indikator tersebut antara lain 1) Komunikasi 2) Mutual reward theory, dan 3) Kehadiran emosi.

\subsection{Hipotesis}

\subsubsection{Pengaruh Positif Workplace Bullying terhadap Turnover Intention}

Menurut Berthelsen et al. (2011) perundungan diindikasikan sebagai pemicu stres ditempat kerja. Stres berkepanjangan yang dialami karyawan di tempat kerja dapat mempengaruhi individu secara negatif, yang mana karyawan akan mengalami kelelahan kerja, mudah marah, agresif, dan frustasi dengan situasi di lingkungan kerja, sehingga dapat mengakibatkan tingkat motivasi, keterlibatan, dan produktivitas yang lebih rendah. Selain itu, bullying di tempat kerja akan mempengaruhi kesehatan karyawannya baik kesehatan secara fisik maupun secara psikis seperti kecemasan, rasa kurang percaya diri bahkan depresi. Hal ini, yang nantinya akan berdampak negatif pada penurunan kinerja karyawan dan produktivitas organisasi.

Temuan penelitian terdahulu menunjukan bahwa karyawan yang mengalami tindakan dari perilaku perundungan akan terjerat dalam lingkaran setan sehingga akan meningkatkan perasaan negatif (Glasø \& Notelaers, 2012). Hasil penelitian dari Coetzee \& van Dyk (2018) menemukan bahwa workplace bullying berpengaruh positif terhadap turnover intention. Ini artinya semakin tinggi perundungan di tempat kerja, maka akan meningkatkan keinginan karyawan untuk keluar dari tempat kerja mereka. Hal ini dikarenakan perilaku perundungan memiliki pengaruh emosional negatif bagi para korban perundungan, menurunkan semangat dan kualitas kerja mereka yang selanjutnya akan meningkatkan niat mereka untuk meninggalkan organisasi (Coetzee \& van Dyk, 2018). Penelitian yang dilakukan oleh Rosario-Hernandez et al. (2018) 
menemukan bahwa workplace bullying berpengaruh secara langsung terhadap turnover intention pada karyawan organisasi swasta dan pemerintah di Puerto Rico.

Apabila karyawan mengalami perundungan di tempat kerja secara terus menerus, maka hal ini akan semakin membuat karyawan merasa tidak nyaman berada di lingkungan kerjanya dan memiliki keinginan yang kuat untuk pindah atau keluar kerja dari tempat dimana dia bekerja saat ini. Hal ini mengindikasikan bahwa pengaruh workplace bullying terhadap turnover intention memiliki arah yang positif. Artinya, apabila tingkat perundungan di tempat kerja tinggi, maka keinginan atau niat karyawan untuk meninggalkan atau pindah organisasi atau perusahaannya pun akan meningkat. Sedangkan apabila perundungan di tempat kerja rendah, maka keinginan atau niat karyawan untuk meninggalkan atau pindah organisasi atau perusahaannya pun akan turun. Hal ini juga diperkuat oleh Glasø \& Notelaers (2012) yang mengatakan bahwa penurunan suasana hati yang positif dan peningkatan emosional negatif dapat menimbulkan keterlibatan dan kepuasan kerja yang lebih rendah dan yang selanjutnya akan meningkatkan turnover intention. Sedangkan menurut Aljawazneh \& Smadi (2017) tidak menemukan adanya pengaruh antara perundungan di tempat kerja dengan keinginan untuk keluar pada perusahaan industri di Yordania. Hal ini dikarenakan banyak pekerja percaya bahwa tidak ada tempat kerja yang bebas dari perundungan, meskipun pengaruh dan intensitasnya berbeda oleh karena itu mereka harus mempertimbangkan faktor lain selain perundungan di tempat kerja yang mempengaruhi keinginan untuk keluar. Penelitian yang dilakukan Glambek et al. (2014) tentang perundungan di tempat kerja sebagai anteseden terhadap niat untuk meninggalkan tempat kerja pada pekerja lepas pantai di Laut Utara Norwegia Berdasarkan inkonsistensi hasil penelitian terdahulu dan teori mengenai pengaruh workplace bullying terhadap turnover intention, maka hipotesis pertama dalam penelitian ini adalah:

\section{$\mathrm{H}_{1}$ : Workplace Bullying Berpengaruh Positif terhadap Turnover Intention}

\subsubsection{Pengaruh Negatif Perceived Supervisor Support terhadap Turnover Intention}

Menurut Eisenberger et al. (2002) perceived supervisor support (PSS) mengacu pada pendapat yang dimiliki pekerja tentang apakah manajer mereka menghargai kontribusi mereka dan peduli terhadap kesejahteraan mereka. Supervisor atau manajer juga dianggap sebagai perwakilan dari organisasi yang memiliki tanggung jawab untuk mengarahkan dan mengevaluasi kinerja para karyawannya sehingga karyawan akan mempersepsikan hal tersebut sebagai indikasi dukungan organisasi (Eisenberger et al., 2002). Menurut Lim \& Boger (2005) dukungan supervisor yang dirasa karyawan atau persepsi dukungan supervisor yang buruk akan sangat merugikan perusahaan karena dapat mengakibatkan tingkat turnover yang tinggi, absensi, dan kinerja yang rendah, sehingga dapat mengurangi keberhasilan organisasi atau perusahaan secara menyeluruh.

Beberapa temuan penelitian mengenai perceived supervisor support terhadap turnover intention antara lain Kalidass \& Bahron (2015) menemukan bahwa perceived supervisor support berpengaruh negatif terhadap turnover intention pada karyawan hotel. Menurut Maertz et al. (2007) perceived supervisor support menjadi salah satu faktor penting dalam memprediksi turnover intention, semakin sedikit dukungan dari supervisor, semakin semakin besar kemungkinan karyawan akan meninggalkan organisasi tempat kerja mereka. Begitu pula penelitian dari Taufiq (2017) dan Arici (2018) yang menunjukkan hasil bahwa perceived supervisor support berpengaruh negatif terhadap turnover intention. Penelitian tersebut menyimpulkan bahwa semakin rendah persepsi dukungan supervisor yang dirasa karyawan, maka semakin tinggi turnover intention atau keinginan karyawan untuk keluar meninggalkan pekerjaannya. 
Begitu pula sebaliknya, semakin tinggi dukungan supervisor yang dirasa, maka tingkat turnover intention semakin rendah. Pada saat yang sama, dukungan supervisor juga secara positif mempengaruhi kesejahteraan subjektif, sehingga mengurangi niat atau keinginan keluar atau berpindah, sesuai hasil penelitian dari Gordon et al. (2019). Berdasarkan penelitian terdahulu dan teori mengenai pengaruh perceived supervisor support terhadap turnover intention, maka hipotesis kedua dalam penelitian ini adalah:

$\mathrm{H}_{2}$ : Perceived Supervisor Support Berpengaruh Negatif terhadap Turnover Intention

\subsection{Model Penelitian}

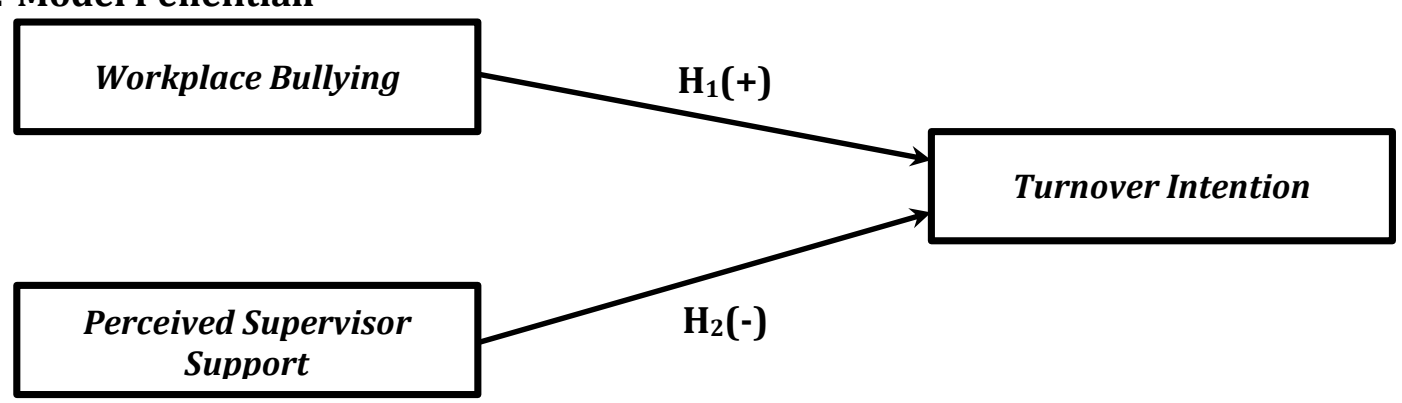

Gambar 1. Model Penelitian

\section{Metode Penelitian}

\subsection{Populasi dan Sampel}

Menurut Nazir (2005) populasi adalah kumpulan dari individu dengan kualitas serta ciri-ciri yang telah ditetapkan. Populasi dalam penelitian ini adalah semua karyawan sebuah universitas swasta di Yogyakarta. Sedangkan sampel adalah bagian dari populasi yang karakteristiknya hendak diteliti yang dipandang sebagai suatu pendugaan terhadap populasi. Sampel dalam penelitian ini adalah sebagian karyawan universitas swasta di Yogyakarta. Teknik pengambilan sampel yang digunakan adalah non-probability sampling dengan metode insidental sampling. Alasan pengambilan sampel dengan metode ini adalah karena penyebaran kuesioner itu menggunakan google form sehingga karyawan yang secara kebetulan atau insidental mengisi form ini dapat digunakan sebagai sampel. Menurut Arikunto (2013) jika jumlah populasinya kurang dari 100 orang, maka jumlah sampelnya diambil secara keseluruhan, tetapi jika populasinya lebih besar dari 100 orang, maka bisa diambil $10-15 \%$ atau $20-25 \%$ dari jumlah populasinya. Dikarenakan populasi dalam penelitian ini berjumlah 300 karyawan, maka penentuan ukuran minimal sampel dihitung dengan $20 \%$ dari 300 yaitu 60 sehingga minimal ukuran sampel penelitian ini adalah 60 karyawan.

\subsection{Pengujian Instrumen Penelitian}

\subsubsection{Uji Validitas dan Uji Reliabilitas}

Pengujian validitas dalam penelitian ini menggunakan confirmatory factor analysis (CFA). Menurut Ghozali (2013) CFA adalah salah satu metode analisis multivariat yang digunakan untuk menguji atau mengkonfirmasikan model yang dihipotesiskan. Dimana syarat data dikatakan valid apabila indikator yang digunakan dalam penelitian mempunyai nilai factor loading > 0,5 dan membentuk satu komponen pada component matrix (Ghozali, 2013). Pengujian reliabilitas dilakukan dengan metode internal consistency yaitu cronbach's alpha. Syarat instrumen penelitian dapat dikatakan reliabel adalah apabila memiliki nilai cronbach's alpha $\geq 0,6$ (Hair et al., 2010). 


\subsubsection{Metode Analisis Data dan Teknik Pengujian Hipotesis}

Metode yang digunakan dalam penelitian ini adalah analisis regresi linear berganda (multiple linear regression). Model persamaan regresi linier berganda untuk penelitian ini adalah:

$\mathrm{Y}=$ Turnover Intention

$$
Y=\alpha+\beta_{1} W B+\beta_{2} P S S
$$

$\alpha=$ Nilai Konstanta

$\beta_{1}, \beta_{2}=$ Nilai Koefisien Variabel

WB $=$ Workplace Bullying

PSS $=$ Perceived Supervisor Support

Pengujian signifikansi hipotesis secara individu atau parsial dapat menggunakan uji $t$ yaitu pengujian untuk mengetahui pengaruh variabel independen terhadap variabel dependen yang diuji pada tingkat signifikansi sebesar $5 \%(0,05)$. Kriteria penerimaan pengujian hipotesis untuk uji $t$ adalah apabila nilai signifikansi lebih kecil $(<)$ dari alpha 5\% $(0,05)$, maka hipotesis diterima. Sebaliknya, apabila nilai signifikansi lebih besar dari $(>)$ dari alpha 5\% $(0,05)$, maka hipotesis ditolak.

\section{Hasil dan Pembahasan}

\subsection{Uji Instrumen}

\subsubsection{Uji Validitas}

Tabel 1. Hasil Uji Validitas Variabel Turnover Intention

\begin{tabular}{|c|c|c|}
\hline Indikator & Nilai Loading Factor & Keterangan \\
\hline TI 1.1 & 0,587 & Valid \\
TI 2.1 & 0,799 & Valid \\
TI 2.2 & 0,846 & Valid \\
TI 2.3 & 0,863 & Valid \\
TI 3.1 & 0,771 & Valid \\
TI 3.2 & 0,834 & Valid \\
TI 3.3 & 0,741 & Valid \\
\hline
\end{tabular}

Sumber: Data Primer Diolah (2021)

Langkah pertama dalam melakukan uji validitas adalah melakukan uji $K M O \&$ Bartlett's Test. Hasil uji KMO \& Bartlett's Test pada variabel turnover intention (TI) sebesar 0,893 >0,6. Tabel 1 menunjukkan hasil uji validitas untuk turnover intention melalui 3 tahap pengujian. Indikator pertanyaan variabel ini pada awalnya terdiri dari 9 indikator pertanyaan setelah diuji pada tahap pertama mengeluarkan indikator pertanyaan dengan nilai MSA terkecil yaitu TI 1.2 dengan nilai 0,808 dan tahap kedua mengeluarkan TI 1.3 dengan nilai MSA terkecil sebesar 0,843 sehingga tersisa 7 indikator pertanyaan yang valid yaitu sudah mengelompok menjadi satu komponen dengan semua item pertanyaan memiliki nilai loading factor $>0,5$. 
Tabel 2. Hasil Uji Validitas Variabel Workplace Bullying

\begin{tabular}{|c|c|c|}
\hline Indikator & Nilai Loading Factor & Keterangan \\
\hline WB 1.1 & 0,833 & Valid \\
WB 1.5 & 0,726 & Valid \\
WB 1.6 & 0,886 & Valid \\
WB 1.7 & 0,843 & Valid \\
WB 2.1 & 0,928 & Valid \\
WB 2.2 & 0,846 & Valid \\
WB2.3 & 0,819 & Valid \\
WB 2.4 & 0,896 & Valid \\
WB 2.5 & 0,907 & Valid \\
WB 2.6 & 0,808 & Valid \\
WB 2.7 & 0,737 & Valid \\
WB 2.8 & 0,873 & Valid \\
WB 2.9 & 0,897 & Valid \\
WB 2.10 & 0,842 & Valid \\
WB 2.11 & 0,904 & Valid \\
WB 2.12 & 0,876 & Valid \\
WB 3.1 & 0,871 & Valid \\
WB 3.2 & 0,722 & Valid \\
WB 3.3 & 0,790 & Valid \\
\hline
\end{tabular}

Sumber: Data Primer Diolah (2021)

Selanjutnya, nilai KMO \& Bartlett's Test pada variabel workplace bullying (WB) sebesar 0,937 >0,6. Tabel 2 di atas bahwa workplace bullying pada awalnya memiliki 22 indikator pertanyaan, setelah melalui uji validitas pada tahap pertama masih mengelompok menjadi dua komponen. Oleh karena itu, diuji kembali dengan mengeluarkan 3 indikator pertanyaan dengan nilai MSA terkecil yaitu WB 1.2 sebesar 0,893; WB 1.3 sebesar 0,901, dan WB 1.4 sebesar 0,921, maka tersisa 19 indikator pertanyaan yang valid yaitu matrik komponen sudah mengelompok menjadi satu faktor komponen memiliki nilai loading factor $>0,5$.

Tabel 3. Hasil Uji Validitas Variabel Perceived Supervisor Support

\begin{tabular}{|c|c|c|}
\hline Indikator & Nilai Loading Factor & Keterangan \\
\hline PSS 1.1 & 0,849 & Valid \\
PSS 1.2 & 0,896 & Valid \\
PSS 2.1 & 0,877 & Valid \\
PSS 3.1 & 0,762 & Valid \\
\hline
\end{tabular}

Sumber: Data Primer Diolah (2021)

Berikutnya, nilai $K M O$ \& Bartlett's Test pada variabel perceived supervisor support (PSS) sebesar 0,774 $>0,6$. Selanjutnya dapat dilihat pada tabel 3 di atas yaitu variabel perceived supervisor support dengan 4 indikator pertanyaan dan langsung mengelompok menjadi satu komponen matrik serta seluruh indikator pertanyaannya memiliki nilai loading factor $>0,5$. Berdasarkan hasil tersebut variabel perceived supervisor support dinyatakan valid. 


\subsubsection{Uji Reliabilitas}

Tabel 4. Hasil Uji Reliabilitas

\begin{tabular}{ccc|}
\hline Variabel & Cronbach's Alpha & Keterangan \\
\hline Turnover Intention & 0,894 & Reliabel \\
Workplace Bullying & 0,976 & Reliabel \\
Perceived Supervisor Support & 0,866 & Reliabel \\
\hline
\end{tabular}

Sumber: Data Primer Diolah (2021)

Berdasarkan tabel 4 dapat dilihat nilai cronbach's alpha masing-masing variabel > 0,6, sehingga dapat disimpulkan bahwa seluruh indikator pertanyaan pada variabel turnover intention, workplace bullying, dan perceived supervisor support reliabel, sehingga ketiga variabel tersebut dapat dilanjutkan untuk pengujian selanjutnya yaitu uji regresi.

\section{2. Analisis Data dan Pengujian Hipotesis}

\subsubsection{Analisis Regresi Linear Berganda}

Tabel 5. Hasil Uji Regresi

\begin{tabular}{c|c|c|}
\hline Variabel & Nilai Koefisien & Nilai Signifikansi \\
\hline (Constant) & 1,458 & 0,022 \\
Workplace Bullying & 0,403 & 0,001 \\
Perceived Supervisor Support & 0,158 & 0,232 \\
\hline
\end{tabular}

Sumber: Data Primer Diolah (2021)

Berdasarkan tabel 5 di atas, maka diperoleh model persamaan regresi untuk penelitian ini:

Keterangan:

$$
(Y)=1,458+0,403 \mathrm{WB}+0,158 \text { PSS }
$$

a. Nilai konstanta sebesar 1,458. Artinya, apabila nilai workplace bullying dan perceived supervisor support dianggap 0, maka nilai turnover intention sebesar 1,458.

b. Koefisien regresi workplace bullying sebesar 0,403 yang berarti setiap kenaikan nilai workplace bullying, maka turnover intention akan mengalami kenaikan sebesar 0,403 .

c. Koefisien regresi perceived supervisor support sebesar 0,158 yang berarti setiap kenaikan nilai perceived supervisor support, maka nilai turnover intention akan mengalami kenaikan sebesar 0,158.

\subsubsection{Pengujian Hipotesis}

\subsubsection{Uji T (Uji Parsial)}

Tabel 6. Hasil Uji T (Uji Parsial)

\begin{tabular}{ccccc|}
\hline Variabel & Nilai Koefisien & Nilai Signifikansi & Keterangan \\
\hline (Constant) & 1,458 & 0,022 & \\
Workplace Bullying & 0,403 & 0,001 & $\mathrm{H}_{1}$ Diterima \\
Perceived Supervisor & 0,158 & 0,232 & $\mathrm{H}_{2}$ Ditolak \\
Support & & & \\
\hline
\end{tabular}

Sumber: Data Primer Diolah (2021)

Berdasarkan hasil uji t pada tabel 6 di atas dapat dijelaskan sebagai berikut:

1. Pengaruh Positif Workplace Bullying terhadap Turnover Intention

Pada tabel 6 dapat dilihat bahwa nilai koefisien untuk workplace bullying sebesar 0,403 dengan nilai signifikansi sebesar 0,001, dimana nilai signifikansi 
tersebut $<0,05$. Hal ini menunjukkan bahwa hipotesis pertama yang mengatakan workplace bullying berpengaruh positif terhadap turnover intention karyawan diterima.

2. Pengaruh Positif Perceived Supervisor Support terhadap Turnover Intention

Pada tabel 6 dapat dilihat bahwa nilai koefisien untuk perceived supervisor support sebesar 0,158 dengan nilai signifikansi sebesar 0,232, dimana nilai signifikansi tersebut $>0,05$. Hal ini menunjukkan bahwa hipotesis kedua yang mengatakan perceived supervisor support tidak berpengaruh terhadap turnover intention karyawan ditolak.

\subsubsection{Uji Koefisien Determinan}

Tabel 7. Hasil Koefisien Determinan

\begin{tabular}{|c|c|}
\hline Model & Nilai $R$-Square \\
\hline 1 & 0,144 \\
\hline
\end{tabular}

Sumber: Data Primer Diolah (2021)

Tabel 7 menunjukkan hasil koefisien determinan dengan nilai $R$-Square sebesar 0,144. Hal ini dapat menunjukkan bahwa variabel workplace bullying dan perceived supervisor support dapat menjelaskan turnover intention sebesar 14,4 \%, sedangkan sisanya sebesar $85,6 \%$ dijelaskan oleh variabel independen lainnya yang tidak diteliti dalam penelitian ini.

\subsection{Pembahasan}

\subsubsection{Pengaruh Positif Workplace Bullying terhadap Turnover Intention}

Penelitian ini searah dengan penelitian yang dilakukan oleh Coetzee \& van Dyk (2018) dimana workplace bullying berpengaruh positif dan signifikan terhadap turnover intention. Pada penelitian ini workplace bullying berpengaruh positif terhadap turnover intention karyawan. Hal ini mengindikasikan bahwa karyawan sebuah universitas swasta setuju apabila mereka mengalami perundungan di tempat mereka bekerja maka keinginan untuk keluar dari tempat kerja mereka juga semakin tinggi. Hal ini dimungkinkan dapat disebabkan dari beberapa faktor yaitu apabila karyawan mendapatkan hinaan dan ejekan atas pekerjaan yang mereka lakukan baik dilakukan oleh sesama rekan kerja atau atasan, mendapatkan komentar dengan nada menghina atau menyinggung mengenai sikap dan kehidupan pribadi karyawan, dan selalu mendapatkan tuduhan atas hal-hal yang karyawan tidak lakukan. Hal ini didukung juga oleh Sims \& Sun (2012) yang mengatakan bahwa semakin sering seorang karyawan mendapat perlakuan perundungan di tempat kerja, maka niat karyawan tersebut untuk keluar dari pekerjaannya akan semakin tinggi. Selain itu, hasil penelitian ini juga didukung oleh Rosario-Hernandez et al. (2018) dimana workplace bullying berpengaruh secara langsung terhadap turnover intention pada karyawan organisasi swasta dan pemerintah di Puerto Rico dan penelitian yang dilakukan Glambek et al. (2014) tentang perundungan di tempat kerja sebagai anteseden terhadap niat untuk meninggalkan tempat kerja pada pekerja lepas pantai di Laut Utara Norwegia.

Dengan adanya perlakuan yang tidak menyenangkan pada tempat kerja, maka karyawan merasa terancam dan mempunyai keinginan keluar dengan memulai mencari lowongan kerja di tempat lain. Selain itu, hal ini dapat makin mendukung keinginan karyawan untuk keluar apabila tempat kerja diluaran sana menjanjikan gaji yang lebih besar dari pada tempat kerja saat ini. Meski hasil penelitian ini mendukung ada pengaruh antara workplace bullying berpengaruh positif dan signifikan terhadap turnover intention bukan berarti pada universitas swasta tersebut ada perundungan karena hal ini dapat dilihat pada hasil kuesioner yang diisi responden menunjukkan 
sebagian besar mengisi "tidak pernah" pada beberapa pertanyaan tentang workplace bullying.

\subsubsection{Pengaruh Negatif Perceived Supervisor Support terhadap Turnover Intention}

Penelitian ini berbanding terbalik dengan penelitian dari Kalidass \& Bahron (2015), Taufiq (2017), dan Arichi (2018) dimana perceived supervisor support berpengaruh signifikan negatif terhadap turnover intention. Pada penelitian ini menunjukkan hasil bahwa perceived supervisor support tidak mempengaruhi turnover intention karyawan sebuah universitas swasta di Yogyakarta. Itu artinya karyawan tidak merasakan dampak yang besar dengan adanya perceived supervisor support terhadap keinginan mereka untuk keluar. Hal ini berarti ada atau tidak adanya dukungan atasan yang dirasa karyawan, maka tidak mempengaruhi keinginan atau niat mereka untuk keluar.

Apabila dilihat dari hasil koefisien determinasi yang sangat kecil yaitu sebesar $14,4 \%$ itu dan sisanya sebesar $85,6 \%$ artinya masih ada variabel diluar perceived supervisor support yang mempengaruhi turnover intention. Hal ini dimungkinkan karena ada faktor lain selain variabel itu misal stres kerja yang tinggi seperti pada hasil penelitian yang dilakukan Sangadji (2020) dimana stres kerja memiliki pengaruh positif terhadap turnover intention pada Bank BUMN di Jawa Timur. Diperkuat oleh penelitian yang dilakukan oleh Yukongdi \& Shrestha (2020) yang menyatakan stres kerja berpengaruh positif terhadap turnover intention pada karyawan bank di Nepal. Stres kerja yang terjadi pada karyawan biasanya disebabkan karena ada tekanan pekerjaan atau perasaan stres seperti merasa tegang atau terkuras secara emosional sehingga akan mengurangi tingkat kepuasan kerja dan meningkatkan niat karyawan berhenti atau pindah dari tempat kerja mereka (Yukongdi \& Shrestha, 2020)

Sama halnya dengan stres kerja, kelelahan kerja (burnout) juga dapat mempengaruhi keinginan karyawan untuk keluar atau pindah dari tempat kerjanya menjadi tinggi. Hal sesuai hasil penelitian dari Rosario-Hernandez et al. (2018) bahwa burnout memiliki pengaruh signifikan positif terhadap turnover intention. Dimana ketika karyawan memiliki pekerjaan yang monoton atau bahkan terlalu dinamis, tidak ada dukungan sosial dan adanya dinamika tempat kerja yang buruk maka akan menimbulkan kelelahan kerja sehingga kinerjanya menurun dan keinginan keluar atau pindah dari tempat kerja makin tinggi.

Selain pengaruh positif dimungkinkan ada pengaruh negatif yang mempengaruhi faktor lingkungan kerja yang kondusif baik dari lingkungan fisik seperti fasilitas yang diberikan oleh universitas tersebut sudah memadai dan juga lingkungan secara non fisik seperti budaya kerja dan rekan kerja yang nyaman. Hal ini sesuai dengan hasil penelitian dari Karyati (2020) yang menunjukkan ada pengaruh signifikan negatif antara lingkungan kerja terhadap turnover intention. Artinya, apabila lingkungan kerja mereka baik, maka keinginan karyawan untuk keluar menjadi rendah. Menurut Mobley et al. (1978) lingkungan kerja merupakan salah satu faktor yang berdampak pada turnover intention. Lingkungan kerja dapat meliputi lingkungan fisik maupun sosial. Lingkungan fisik meliputi keadaan suhu, cuaca, kontruksi, bangunan, dan lokasi pekerjaan, sedangkan lingkungan sosial meliputi sosial budaya di lingkungan kerjanya dan kualitas kehidupan kerjanya. 


\section{Kesimpulan dan Saran}

\subsection{Kesimpulan}

Berdasarkan hasil penelitian dapat ditarik kesimpulan bahwa hipotesis pertama diterima yaitu workplace bullying berpengaruh positif terhadap turnover intention di lingkungan universitas swasta di Yogyakarta. Selanjutnya hipotesis kedua ditolak yaitu perceived supervisor support tidak berpengaruh terhadap turnover intention di lingkungan universitas swasta di Yogyakarta.

\subsection{Saran}

Saran untuk sebuah universitas swasta di Yogyakarta, sebaiknya para pimpinan untuk lebih memperhatikan karyawannya dengan memberikan dukungan dan perhatian pada kinerja mereka sehingga perceived supervisor support karyawan akan meningkat dan keinginan karyawan untuk keluar dari universitas semakin kecil. Selain itu, segenap civitas akademika universitas untuk menangani masalah perundungan, jangan sampai perundungan terjadi di lingkungan universitas swasta tersebut.

Sedangkan untuk penelitian selanjutnya bisa menambahkan sampel sesuai dengan populasi sehingga minimal jumlah responden dapat terpenuhi. Berikutnya dikarenakan nilai koefisien determinasi sangat kecil yaitu 14,4\%, sehingga masih ada 85,6 \% variabel lain yang mempengaruhi turnover intention. Maka dari itu, untuk penelitian selanjutnya dapat menambahkan variabel independen lainnya yang mempengaruhi turnover intention misalkan komitmen organisasi, kelelahan kerja, stres kerja, dan lingkungan kerja.

\section{Daftar Pustaka}

Aljawazneh, B., \& Ziad, S. (2017). Workplace Bullying As A Predictor Of Intention To Leave Among Workers At The Industrial Organizations In Jordan. International Research in Economics and Management Sciences, 6(1), 15-39.

Arikunto, S. (2013). Prosedur Penelitian: Suatu Pendekatan Praktik. Rineka Cipta.

Arici, H. E. (2018). Perceived Supervisor Support and Turnover Intention Moderating Effect Of Authentic Leadership. Leadership and Organization Development Journal, 39(7).

Bacharach, S. B., \& Bamberger, P. A. (2007). 9/11 And New York City Firefighters' Post Hoc Unit Support And Control Climates: A Context Theory Of The Consequences Of Involvement In Traumatic Work-Related Events. Academy of Management Journal, 50(4), 849-868.

Berthelsen, M., Skogstad, A., Lau, B., \& Einarsen, S. (2011). Do They Stay Or Do They Go? A Longitudinal Study Of Intentions To Leave And Exclusion From Working Life Among Targets Of Workplace Bullying. International Journal of Manpower, 32(2).

Chen, Z. X., Tsui, A. S., \& Farh, J. L. (2002). Loyalty To Supervisor Vs Organizational Commitment: Relationships To Employee Performance In China. Journal Of Occupational And Organizational Psychology, 75(3), 339-356.

Coetzee, M., \& van Dyk, J. (2018). Workplace Bullying And Turnover Intention: Exploring Work Engagement As A Potential Mediator. Psychological Reports, 121(2), 375-392.

Dasgupta, P. (2012). Effect Of Role Ambiguity, Conflict And Overload In Private Hospitals' Nurses' Burnout And Mediation Through Self Efficacy. Journal of Health Management, 14(4), 513-534.

Dysvik, A., \& Kuvaas, B. (2010). Exploring The Relative and Combined Influence of MasteryApproach Goals and Work Intrinsic Motivation on Employee Turnover Intention. Personal Review, 39(5). 
Einarsen, S., Hoel, H., \& Notelaers, G. (2009). Measuring Exposure To Bullying And Harassment At Work: Validity, Factor Structure And Psychometric Properties of The Negative Acts Questionnaire-Revised. Work \& Stress, 23(1), 24-44.

Eisenberger, R., Stinglhamber, F., Vandenberghe, C., Sucharski, I. L., \& Rhoades, L. (2002). Perceived Supervisor Support: Contributions To Perceived Organizational Support And Employee Retention. Journal Of Applied Psychology, 87(3), 565.

Ferdinand, A. (2010). Pendidikan, Pengaruh Pembinaan Sumber Daya Manusia Terhadap Kinerja Pegawai. Management Analysis Journal, 2(2).

Glambek, M., Matthiesen, S. B., Hetland, J., \& Einarsen, S. (2014). Workplace Bullying As An Antecedent To Job Insecurity And Intention To Leave: A 6-Month Prospective Study. Human Resource Management Journal, 24(3), 255-268.

Ghozali, I. (2013). Aplikasi Analisis Multivariate dengan Program IBM SPSS 19 Edisi Kelima. Badan Penerbit Universitas Diponegoro.

Glasø, L., \& Notelaers, G. (2012). Workplace Bullying, Emotions, And Outcomes. Violence And Victims, 27(3), 360-377.

Gordon, S., Tang, C. H. H., Day, J., \& Adler, H. (2019). Supervisor Support And Turnover In Hotels: Does Subjective Well-Being Mediate The Relationship?. International Journal of Contemporary Hospitality Management.

Hair, J.F., Tatham, A.R.L., \& Black, W.C. (2011). Multivariate Data Analysis (5th Edition). Prentice Hall.

Hasibuan, M. (2003). Organisasi dan Motivasi Dasar Peningkatan Produktivitas. Bumi Aksara.

Hershcovis, M. S., Reich, T. C., \& Niven, K. (2015). Workplace Bullying: Causes, Consequences, and Intervention Strategies. Society for Industrial and Organizational Psychology, Inc.

Kalidass, A., \& Bahron, A. (2015). The Relationship Between Perceived Supervisor Support, Perceived Organizational Support, Organizational Commitment And Employee Turnover Intention. International Journal of Business Administration, 6(5), 82.

Karyati, T. (2019). Pengaruh Kepuasan Kerja Dan Stres Kerja Terhadap Turnover Intention Pada Karyawan Dehakidz Darul Hikam Daycare And Learning Center Bandung (Doctoral dissertation, UIN Sunan Gunung Djati Bandung).

Keashly, L., \& Neuman, J. H. (2004). Bullying In The Workplace: Its Impact And Management. Employee Rights and Employment Policy Journal, 8(2), 335.

Lim, E., \& Boger, E. P. (2005). Management Requires Leadership. Consortium Journal of Hospitality \& Tourism, $9(1)$.

Luthans, F. (2012). Organization Behavior: An Evidence-Based Approach. McGraw-Hill.

Maertz Jr, C. P., Griffeth, R. W., Campbell, N. S., \& Allen, D. G. (2007). The Effects Of Perceived Organizational Support And Perceived Supervisor Support On Employee Turnover. Journal of Organizational Behavior: The International Journal of Industrial, Occupational and Organizational Psychology and Behavior, 28(8), 1059-1075.

Mahardika, I. G. A. G. E., \& Wibawa, I. M. A. (2015). Pengaruh Kepuasan Kerja terhadap Turnover Intention dengan Komitmen Organisasi sebagai Variabel Intervening pada PT. Autobagus Rent Car Bali. Doctoral dissertation, Universitas Udayana.

Mathis, R. L., \& Jackson, J. H. (2006). Human Resource Management. Terjemahan Dian Angelia. Salemba Empat.

Mathisen, G. E., Einarsen, S., \& Mykletun, R. (2008). The Occurrences And Correlates Of Bullying And Harassment In The Restaurant Sector. Scandinavian Journal Of Psychology, 49(1), 59-68. 
Melky, Y. (2015). Hubungan Kepuasan Kerja dan Komitmen Organisasi terhadap Intensi Pindah Kerja (Turnover Intention) Karyawan PT Rejeki Abadi Sakti Samarinda. Psikoborneo: Jurnal Ilmiah Psikologi, 3(1).

Mobley, W. H., Horner, S. O., \& Hollingsworth, A. T. (1978). An Evaluation Of Precursors Of Hospital Employee Turnover. Journal Of Applied Psychology, 63(4), 408.

Nazir, M. (2005). Metode Penelitian. Ghalia Indonesia.

Robbins, S. P., \& Judge, T. A. (2013). Organizational Behavior. Pearson Education.

Rosario-Hernández, E., Rovira Millán, L. V., Comas Nazario, Á. R., Medina Hernández, A., Colón Jiménez, R., Feliciano Rivera, Y., ... \& Berrios Quiñones, G. (2018). Workplace Bullying And Its Effect On Sleep Well-Being: The Mediating Role Of Rumination. Revista Puertorriqueña de Psicología.

Sangadji, E. M. (2020). The Effect Of Job Stress On Turnover Intention Through Job Satisfaction Of Government Commercial Bank Employees. KnE Social Sciences, 66-82.

Sims, R. L., \& Sun, P. (2012). Witnessing Workplace Bullying And The Chinese Manufacturing Employee. Journal of Managerial Psychology, 27.

Taufiq, A. (2017). Pengaruh Persepsi Dukungan Supervisor dan Komitmen Organisasi terhadap Turnover Intention (Studi pada Pegawai Bagian Produksi PT. Mitra Adi Jaya Yogyakarta) (Doctoral dissertation, Universitas Negeri Yogyakarta).

Tett, R. P., \& Meyer, J. P. (1993). Job Satisfaction, Organizational Commitment, Turnover Intention, And Turnover: Path Analyses Based On Meta-Analytic Findings. Personnel Psychology, 46(2), 259-293.

Yukongdi, V., \& Shrestha, P. (2020). The Influence Of Affective Commitment, Job Satisfaction And Job Stress On Turnover Intention: A Study Of Nepalese Bank Employees. Review of Integrative Business and Economics Research, 9, 88-98.

Yun, S., Kang, J., Lee, Y. O., \& Yi, Y. (2014). Work Environment And Workplace Bullying Among Korean Intensive Care Unit Nurses. Asian Nursing Research, 8(3), 219-225. 